\title{
Peromyscus leucopus mouse brain transcriptome response to Powassan virus infection
}

\author{
Luwanika Mlera $^{1}$ (D) $\cdot$ Kimberly Meade-White $^{2} \cdot$ Eric Dahlstrom $^{3} \cdot$ Rachel Baur $^{3}$. \\ Kishore Kanakabandi ${ }^{3} \cdot$ Kimmo Virtaneva $^{3} \cdot$ Stephen F. Porcella ${ }^{3}$ - Marshall E. Bloom ${ }^{1}$
}

Received: 11 August 2017 /Revised: 29 September 2017 / Accepted: 25 October 2017 / Published online: 16 November 2017

(C) The Author(s) 2017. This article is an open access publication

\begin{abstract}
Powassan virus (POWV) is a tick-borne Flavivirus responsible for life-threatening encephalitis in North America and some regions of Russia. The ticks that have been reported to transmit the virus belong to the Ixodes species, and they feed on small-to-medium-sized mammals, such as Peromyscus leucopus mice, skunks, and woodchucks. We previously developed a P. leucopus mouse model of POWV infection, and the model is characterized by a lack of clinical signs of disease following intraperitoneal or intracranial inoculation. However, intracranial inoculation results in mild subclinical encephalitis from 5 days post infection (dpi), but the encephalitis resolves by $28 \mathrm{dpi}$. We used RNA sequencing to profile the P. leucopus mouse brain transcriptome at different time points after intracranial challenge with POWV. At $24 \mathrm{~h}$ post infection, 42 genes were significantly differentially expressed and the number peaked to 232 at 7 dpi before declining to 31 at 28 dpi. Using Ingenuity Pathway Analysis, we determined that the genes that were significantly expressed from 1 to $15 \mathrm{dpi}$ were mainly associated with interferon signaling. As a result, many interferon-stimulated genes (ISGs) were upregulated. Some of the ISGs include an array of TRIMs (genes encoding tripartite motif proteins). These results will be useful for the identification of POWV restriction factors.
\end{abstract}

Luwanika Mlera

Luwanika.Mlera@nih.gov

1 Biology of Vector-Borne Viruses Section, Laboratory of Virology, Rocky Mountain Laboratories, NIAID/NIH, Hamilton, MT 59840, USA

2 Rocky Mountain Veterinary Branch, Rocky Mountain Laboratories, NIAID/NIH, Hamilton, MT 59840, USA

3 Genomics Unit, Research Technologies Branch, Rocky Mountain Laboratories, NIAID/NIH, Hamilton, MT 59840, USA
Keywords Powassan virus · Tick-borne flavivirus · Peromyscus lecuopus mouse $\cdot$ Brain transcriptome Differential gene expression · Interferon signaling

\section{Introduction}

Powassan virus (POWV) is a neurotropic tick-borne Flavivirus (TBFV) responsible for life-threatening meningoencephalitis with necrotizing inflammation and lymphocytic infiltrations in humans (Gholam et al. 1999; McLean and Donohue 1959; Piantadosi et al. 2015). The virus is closely related to deer tick virus (DTV or POWV lineage II), and both belong to the tick-borne encephalitis virus (TBEV) serogroup. POWV was initially described in 1958 in a fatal case involving a 5-year-old boy in the small town of Powassan, Ontario, Canada (McLean and Donohue 1959). Although POWV infections in the USA are sporadic, cases have been reported in several states, such as Connecticut, New York State, New Hampshire, and Massachusetts (Deardorff et al. 2013; Ebel 2010; Hermance and Thangamani 2017; Leonova et al. 2009; Lindsey et al. 2015; Pastula et al. 2016; Piantadosi et al. 2015; Simon et al. 2013). In recent months, additional cases of POWV encephalitis have been reported in the Northeastern United States and some were fatal. POWV is also a significant cause of illness in eastern regions of Russia (Deardorff et al. 2013). The incidence of human cases appears to be on the increase (Deardorff et al. 2013; Ebel 2010; Hinten et al. 2008; Piantadosi et al. 2015). An effective vaccine against the TBEV serogroup is available mainly in Europe, but up to 15,000 new infections continue to be recorded annually, leading to death in close to $40 \%$ of infected cases depending on the TBEV strain (Dobler 2010; Heinz and Kunz 2004; Heinz et al. 2013). 
In almost all cases, the ticks that have been shown to transmit TBFVs including POWV belong to the Ixodes genus. These ticks typically feed on small-to-medium-sized mammals, such as white-footed mice or Peromyscus leucopus, striped field mice (Apodemus agrarius), skunks (Mephitis mephitis), and woodchucks (Marmota monax) (Dupuis II et al. 2013; Ebel 2010; Kim et al. 2008; Main et al. 1979; Mlera et al. 2014; Perkins et al. 2003). Evidence implicating these mammals as reservoirs, bridge, or amplification hosts for TBFVs is inconsistent and includes the isolation of the TBEV strain A104 from the brains of wild-caught yellownecked mice (Apodemus flavicollis) in Austria (Frey et al. 2013). The TBEV strains Oshima 08-As and Oshima A-1 were isolated from spleens of captured Apodemus speciosus, and the Oshima C-1 strain from the gray-backed vole Clethrionomys rufocanus in Japan (Kentaro et al. 2013; Takeda et al. 1999). A report from South Korea describes PCR detection and TBEV isolation from lung and spleen tissue obtained from wild Apodemus agrarius mice (Kim et al. 2008). In addition, scientists in Finland detected TBEV RNA in mouse brains, but some mice that had viral RNA were seronegative (Tonteri et al. 2011). Indirect serological evidence suggesting exposure to TBFVs in wild rodents includes the detection of anti-POWV antibodies in wild-caught Peromyscus truei and Peromyscus maniculatus in New Mexico, Myodes rutilus in Siberia and Alaska, and Myodes gapperi in Southern Alaska (Deardorff et al. 2013). Recent surveys have also found evidence of antibodies against POWV in $4.2 \%$ of Eastern US white tail deer, suggesting that virus-infected ticks might also be feeding on this large mammal (Pedersen et al. 2017). In addition to transmitting virus to the mammalian host, infected ticks can also rapidly infect naïve ticks feeding in proximity via a process called "cofeeding" (Labuda et al. 1993a, 1997, 1993b). Thus, the nature of the interaction between arthropod hosts, potential reservoir species, and virus remains uncertain.

Mice belonging to the Peromyscus genus, particularly P. leucopus and P. maniculatus species, are the most abundant mixed-forest rodents in the USA (Bedford and Hoekstra 2015). However, very little is known about the specific role that these mice play in POWV biology. Our initial effort to decipher this role was the development of a P. leucopus model of POWV infection, which is characterized by a lack of overt clinical signs of disease following intraperitoneal or intracranial challenge (Mlera et al. 2017). However, intracranial challenge of $P$. leucopus mice leads to mild subclinical encephalitis at early time points ( 5 to 15 days post infection (dpi)), but the inflammation resolves by $28 \mathrm{dpi}$ (Mlera et al. 2017). These observations starkly contrasted with inbred laboratory mouse strains $\mathrm{C} 57 \mathrm{BL} / 6$ and $\mathrm{BALB} / \mathrm{c}$, which succumb to severe and fatal neurological disease upon intracranial inoculation, recapitulating some aspects of human disease (Hermance and Thangamani 2015; Mlera et al. 2017; Santos et al. 2016).
To extend our studies and to characterize the mild encephalitic response in P. leucopus mouse brains, we used RNA sequencing (RNA-Seq) to profile the differential transcriptome changes associated with POWV infection. Our results indicate that POWV induces the differential expression of many genes and the P. leucopus mice mount a robust interferon response against the virus in a tightly regulated manner. These results will be useful for identification of factors that that have a role in restricting POWV.

\section{Methods}

\section{P. leucopus mouse brain samples}

This study was an extension of our previous work in which we intracranially inoculated 4-week-old $P$. leucopus mice with $10^{3} \mathrm{PFU}$ of POWV LB strain, or serum-free DMEM for controls, followed by euthanasia at 1, 3, 5, 7, 15, and 28 dpi (Mlera et al. 2017). At each time point, we infected three mice with POWV, and three mice were mock-infected controls. All mouse work was ethically done in animal biosafety level 3 (BSL3) facilities according to approved animal study protocols, which are stated in a previous report (Mlera et al. 2017). At necropsy, brain tissue samples from POWV-infected mice and controls for deep sequencing were placed into $1 \mathrm{ml}$ of TRIzol, homogenized, and stored at $-80^{\circ} \mathrm{C}$ until total RNA extraction.

\section{Total brain RNA extraction}

A $200-\mu \mathrm{L}$ aliquot of the brain homogenate was combined with $800 \mu \mathrm{L}$ of TRIzol (Thermo Fisher Scientific, Waltham, MA) and $200 \mu \mathrm{L}$ 1-bromo-3-chloropropane (Sigma-Aldrich, St. Louis, MO), mixed, and centrifuged at $4{ }^{\circ} \mathrm{C}$ at $16,000 \times g$ for $15 \mathrm{~min}$. The aqueous phase was added to QIAshredder columns (Qiagen, Valencia, CA) and centrifuged at $21,000 \times g$ for 2 min to fragment any remaining genomic DNA (gDNA) in the sample. The flow-through was combined with an equal volume of RLT buffer (Qiagen, Valencia, CA) with $1 \% \beta$-mercaptoethanol, and RNA was extracted using AllPrep DNA/RNA 96 Kit as described by the manufacturer (Qiagen, Valencia, CA) including additional on-column DNase 1 treatment to remove gDNA. RNA purity and concentration was determined by spectrophotometry. RNA integrity was analyzed using Agilent 2100 Bioanalyzer (Agilent Technologies, Santa Clara, CA). Equal amounts of RNA $(400 \mathrm{ng})$ were used as a template for NGS library preparation.

\section{RNA-Seq and data analysis}

Host mRNA sequencing used the Illumina TruSeq RNA Sample Preparation Kit v2 (Illumina, San Diego, CA), beginning at the poly-A selection step. Libraries were bar coded, 
amplification cycles were reduced to 10 , and libraries were run as a pool across all eight lanes of the HiSeq 2500 sequencer (Illumina, San Diego, CA).

The generated RNA-Seq reads for each mouse brain were trimmed of adaptor and poor quality sequences and mapped against the P. maniculatus genome (assembly Pman_1.0) using TopHat 2 software (Kim et al. 2013). We aligned the RNA-Seq reads to the genome of $P$. maniculatus because a complete $P$. leucopus genome is currently not available. We also mapped the RNA-Seq reads to the genomes of the rat (Rattus norvegicus assembly Rnor_6.0), the house mouse (Mus musculus assembly GRCm38.p5), and the Chinese hamster (Cricetulus griseus assembly CriGri_1.0). Using the Basic Logic Alignment Search Tool (BLAST; https://blast.ncbi.nlm. nih.gov), we compared selected amino acid sequences of $P$. leucopus proteins deposited in GenBank to those of $P$. maniculatus, Rattus norvegicus, Mus musculus, and Cricetulus griseus.

Transcript quantification and differential gene expression analysis was performed for each POWV-infected mouse using the Cufflinks software suite (Trapnell et al. 2013). The triplicate data for each time point were filtered at \pm 2 -fold change and a false discovery rate (FDR) or corrected $p$ value ( $q$ value) of $<0.05$. Filtered data were used to generate pathways, networks, and functional inference using Qiagen's Ingenuity ${ }^{\circledR}$ Pathway Analysis $\left(\mathrm{IPA}^{\circledR}\right.$ ) software (Qiagen Redwood City; www.qiagen. com/ingenuity). The sequence data were submitted to the National Center for Biotechnology Information Small Read Archive (http://www.ncbi.nlm.nih.gov/Traces/sra/), BioProject number PRJNA395043.

\section{qPCR validation of RNA-Seq data}

We selected four genes for qRT-PCR validation of RNA-Seq data, and these were STAT2, IFIT3, DDX58, and TRIM21. The glycyl-tRNA synthetase gene (GARS) was used to normalize the relative expression of the target genes based on CV across the entire sample set, gene function, and expression level. The Express qPCR SuperMix Universal with premixed ROX (Life Technologies, Carlsbad, CA) was used to perform the qRTPCR assay. The reactions were carried out in $20-\mu \mathrm{L}$ reactions using forward primer and reverse primers and a fluorescent probe (Table 6). All reactions were performed in triplicate, and no template controls were included in each run. The qRT-PCR reactions were carried out at $50^{\circ} \mathrm{C}$ for $2 \mathrm{~min}, 95^{\circ} \mathrm{C}$ for $2 \mathrm{~min}$, 55 cycles of $95^{\circ} \mathrm{C}$ for $15 \mathrm{~s}$, and $60^{\circ} \mathrm{C}$ for $1 \mathrm{~min}$. Data was analyzed using ABI 7900HT (version 2.4) sequence detection system software (Life Technologies, Carlsbad, CA). The Spearman correlation was calculated using GraphPad Prism 7.01 (GraphPad Prism, La Jolla, CA).

\section{Results}

\section{Alignment of the $P$. leucopus RNA-Seq reads to reference genomes}

A complete $P$. leucopus mouse genome is currently unavailable. Thus, we mapped all the $P$. leucopus sequences generated from our RNA-Seq sequencing to the genomes of $P$. maniculatus (deer mouse), Rattus norvegicus (rat), Mus musculus (house mouse), and Cricetulus griseus (Chinese hamster). Approximately $60 \%$ of the $P$. leucopus RNA-Seq reads aligned to the $P$. maniculatus genome, but $<10 \%$ of the reads could be mapped to the genomes of the rat, the house mouse, or the Chinese hamster. In addition, GenBank amino acid sequences of $P$. leucopus MAVS, IFNAR1, STAT1, TRIM30D, and IRF1 (interferon regulatory factor 1 ) proteins were 87, 81, 94, 79, and 99\% identical to their counterpart P. maniculatus sequences, respectively. The TRIM30D sequence from $P$. leucopus was the one most closely related to TRIM30D sequences from the other species at $92 \%$ sequence identity. The MAVS, IFNAR1, STAT1, and IRF1 sequences were divergent (55-89\% sequence identity). Thus, these results suggested that the $P$. maniculatus genome was like that of $P$. leucopus as expected and that it could be used to infer our RNA-Seq data.

\section{Analysis of significantly differentially expressed genes during early POWV infection.}

In our previous study, we observed mild encephalitis in P. leucopus mouse brains from 5 to 15 dpi (Mlera et al. 2017). Defining early POWV infection as the period from 1 to 7 dpi following intracranial (ic) inoculation, we determined the number of significantly differentially expressed genes in comparison to mock-infected animals. Significance was called using a false discovery rate or $q$ value of 0.05 - and \pm 2 -fold change in gene expression. One day after ic infection, 39 genes had increased in expression level, whereas 3 were downregulated (Fig. 1a, Table 1). HIST1H2BA (histone cluster $1 \mathrm{H} 2 \mathrm{~B}$ family member A), HIST1H4A (histone cluster 1 $\mathrm{H} 4$ family member A), and $I S C U$ (iron-sulfur cluster assembly enzyme) were the downregulated genes.

At 3 dpi, only 2 of 109 genes with significant changes in expression were downregulated, and these were HIST1H4A and $C O X 5 B$ (cytochrome $\mathrm{C}$ oxidase subunit 5B). The number of genes with significant changes in expression peaked at $7 \mathrm{dpi}$, but only four were downregulated, CRB1 (crumbs 1), ADAMTS19 (ADAM metallopeptidase with thrombospondin type 1 motif 19), FRMD7 (FERM domain containing 7), and PRDX6 (peroxiredoxin 6). Thus, these data indicated a progressive increase in the number of genes whose expression was induced from 1 to $7 \mathrm{dpi}$.

We evaluated the genes that were commonly expressed at all time points from 1 to $7 \mathrm{dpi}$ and depicted the results in a 

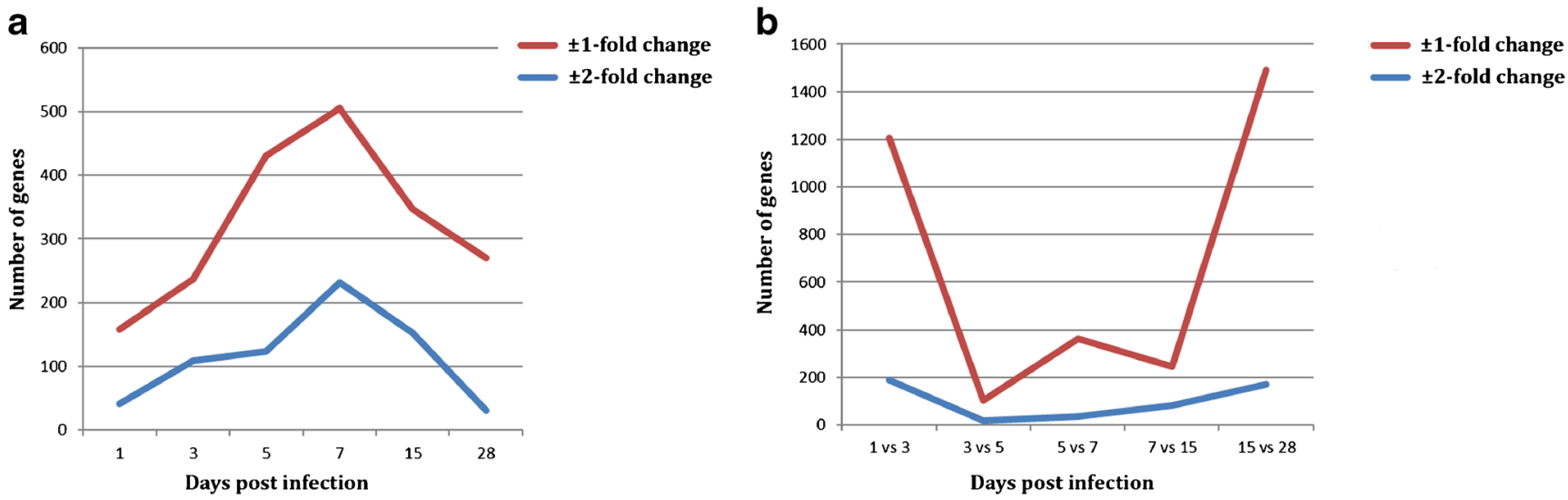

C

\section{d}
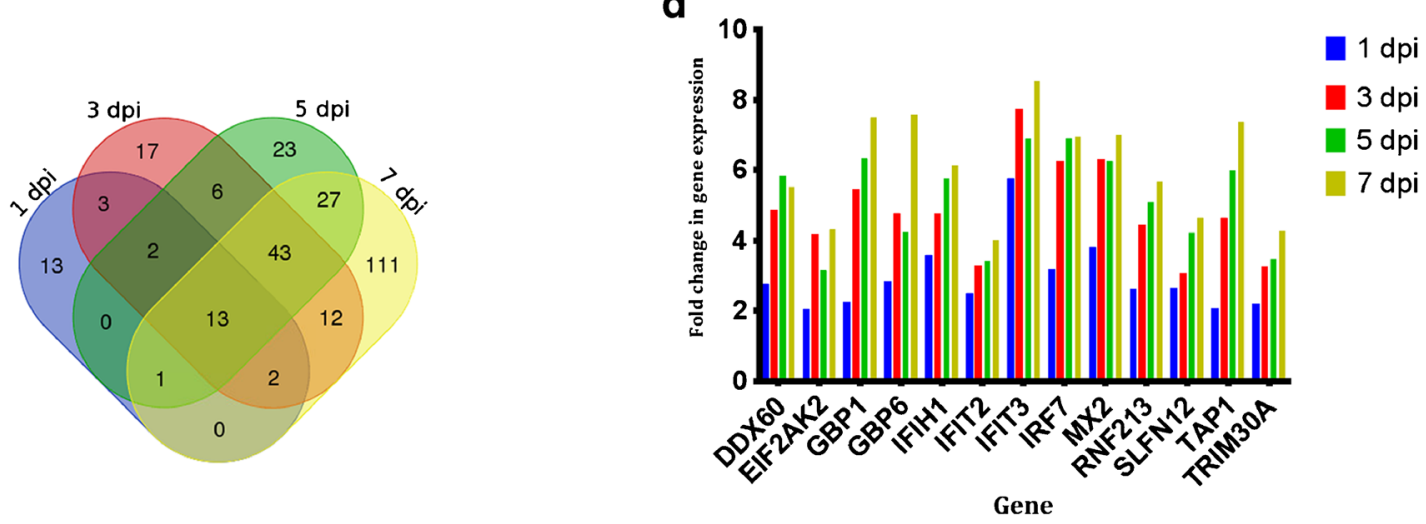

Fig. 1 Overview of the differential gene expression at different time points following POWV challenge in P. leucopus mice. a The trend in the number of genes that were significantly differentially expressed in P. leucopus mouse brains in comparison to uninfected controls. b Comparison of the gene expression profiles of POWV-infected mouse

Venn diagram (Fig. 1c). Thirteen genes were common to all early POWV infection time points. These genes fell into two main families: (a) genes involved in RNA sensing, i.e., $D D X 60$ (DExD/H-box helicase 60) and EIF2AK2 (eukaryotic translation initiation factor 2 alpha kinase 2), and (b) genes with known antiviral properties, i.e., IFIT2 (interferon-

Table 1 Summary of the number of genes that were significantly differentially expressed in P. leucopus mouse brains following inoculation with POWV in comparison to the mock-inoculated brains

\section{Days post infection

\begin{tabular}{llllll}
\hline 1 & 3 & 5 & 7 & 15 & 28
\end{tabular}

${\text { Number of genes at } \pm 2 \text {-fold change }{ }^{\mathrm{a}}}^{42} \quad 109 \quad 124 \quad 232 \quad 153 \quad 31$

$\begin{array}{llllllll}\text { Number of genes at } \pm 1 \text {-fold change }^{\mathrm{b}} & 159 & 237 & 431 & 505 & 347 & 270\end{array}$

Total significant genes

$\begin{array}{llllll}379 & 371 & 715 & 787 & 451 & 2031\end{array}$

${ }^{\text {a }}$ The \pm 2 -fold change denotes gene expression levels higher than 2-fold upregulation or lower than -2-fold downregulation

${ }^{\mathrm{b}}$ The \pm 1 -fold change denotes gene expression levels higher than 1 (including a 2 -fold increase) or lower than -1 (including -2 -fold downregulation) brains. $\mathbf{c}$ Venn diagram showing the number of genes ( \pm 2-fold change in expression) which were common or different during POWV infection from 1 to 7 dpi. d Differential expression of the 13 genes that was common to the 1-, 3-, 5-, and 7-dpi time points. The expression levels were relative to the mock-infected samples

induced protein with tetratricopeptide repeats 2), IFIT3, TRIM30A (tripartite motif containing 30A, a TRIM5 $\alpha$ homo$\log$ ), $M X 2$ (myxovirus resistance protein 2), IFIH1 (interferon induced with helicase $\mathrm{C}$ domain 1), GBP1 (guanylate-binding protein 1), GBP4, and GBP6. Other genes common to the early time points included SFLN12 (schlafen 12), RNF213 (ring finger protein 213), and $I R F 7$. Expression levels of some of these genes at each time point are shown in Fig. 1d, and the clear general trend was an increase in fold change over time.

\section{Analysis of significant gene expression at $15 \mathrm{dpi}$}

We set 15 dpi as the midpoint between the early infection period and the experimental endpoint ( $28 \mathrm{dpi})$. This was the time at which encephalitis was more pronounced as shown by histopathological examination of brain tissue sections (Mlera et al. 2017). At this time point, 153 genes were significantly upregulated (Fig. 1a, Table 1), and none were downregulated. Several RNA-sensing dead-box helicases were upregulated at 15 dpi; DDX60 (3.2-fold) and DHX58 (DExH-box helicase 58, 2.6-fold). In addition, six genes (SLFN12, MX2, 
TRIM30A, GBP1, GBP6, and IFIH1) were common to $15 \mathrm{dpi}$ and the early infection period. In total, 49 of the 153 genes that were significantly upregulated at $15 \mathrm{dpi}$ were unique to this time point, and the overall level of gene activation was reduced.

\section{Analysis of significant gene expression at $28 \mathrm{dpi}$}

We previously showed that POWV RNA persisted in $P$. leucopus mouse brains at an average of 778 copies/ $\mu g$ of total RNA at 28 dpi following ic inoculation, corresponding to $\sim 0.004$ genomes/cell (Mlera et al. 2017). Thus, we examined the differential gene expression at $28 \mathrm{dpi}$ to gain insight into the $P$. leucopus mouse brain response to this residual viral RNA. The results showed that the total number of RNAsensing helicases that were significantly differentially expressed $(q<0.05)$ was higher than the earlier time points, but the range of expression levels was lower than +2 -fold and higher than -2 -fold change. The DExD-box helicases whose expression levels were up $(>0$ and $+2<)$ were $D D X 17$, $D D X 18, D D X 26, D D X 46, D D X 52$, and $D D X 58$, and the fold change was in the range 0.42 to 0.67 . In contrast, other RNAsensing helicases, such as $D D X 23, D D X 27, D D X 49$, and $D D X 54$, were downregulated with the fold change in the range -0.70 to -0.46 . These results suggested that the small amount of viral RNA still present was sufficient to impact pathogen recognition receptor sensing.

Thirty-one genes were significantly differentially upregulated at \pm 2 -fold change at 28 dpi (Table 1, Fig. 1), whereas only two genes, FOXO6 (forkhead box O6) and HIST1H4A, were downregulated. Both FOXO6 and HIST1H4A are involved in transcription regulation. Only $M X 2, C P$ (ceruloplas$\mathrm{min}$ ), and $\mathrm{H2}-\mathrm{Ea}$ (H-2 class II histocompatibility antigen, E-D alpha chain) in the upregulated gene set overlapped with any of the earlier time points from 1 to $15 \mathrm{dpi}$.

Compared to earlier time points, the most dramatic difference in the number of genes was observed between 15 and 28 dpi where 170 genes were different at \pm 2 -fold (Fig. 1b, Table 2). Thus, these results indicated that the transcriptome profile of $P$. leucopus mouse brains at 28 dpi was dramatically different from early infection time points.

\section{Ingenuity Pathway Analysis of the P. leucopus brain response to $\mathrm{POWV}$}

Using a systems biology approach, we employed the IPA software to interrogate the canonical pathways responding to POWV infection in the brains of $P$. leucopus mice. We present the top 5 canonical pathways (based on $p$ value) that were part of the POWV response in the brains as presented in Table 3. One pathway hit during early infection time points was "The role of pathogen recognition receptors (PRRs) in the recognition of bacteria and viruses" (Table 3). The PRRs, in turn, induce the interferon signaling system. Thus, it was important to note that
Table 2 Comparison of significant gene expression between the POWV-inoculated mouse brains over time

\begin{tabular}{|c|c|c|c|c|c|}
\hline & \multicolumn{5}{|c|}{ Time points compared } \\
\hline & $\begin{array}{l}1 \mathrm{vs} \\
3 \mathrm{dpi}\end{array}$ & $\begin{array}{l}3 \mathrm{vs} \\
5 \mathrm{dpi}\end{array}$ & $\begin{array}{l}5 \mathrm{vs} \\
7 \mathrm{dpi}\end{array}$ & $\begin{array}{l}7 \mathrm{vs} \\
15 \mathrm{dpi}\end{array}$ & $\begin{array}{l}15 \mathrm{vs} \\
28 \mathrm{dpi}\end{array}$ \\
\hline $\begin{array}{l}\text { Number of genes at } \\
\pm 2 \text {-fold change }\end{array}$ & 189 & 17 & 36 & 81 & 170 \\
\hline $\begin{array}{l}\text { Number of genes at } \\
\pm 1 \text {-fold change }\end{array}$ & 1207 & 102 & 364 & 246 & 1490 \\
\hline Total significant genes & 2988 & 116 & 411 & 273 & 4299 \\
\hline
\end{tabular}

Table 3 Summary of top 5 canonical pathways inferred from the IPA over the course of POWV infection in the brains of P. leucopus mice

\begin{tabular}{|c|c|c|}
\hline $\begin{array}{l}\text { Time } \\
\text { (dpi) }\end{array}$ & Canonical pathway & $p$ value \\
\hline \multirow[t]{5}{*}{1} & $\begin{array}{l}\text { Role of PRRs in the recognition of bacteria and } \\
\text { viruses }\end{array}$ & $3.47 E-05$ \\
\hline & Activation of IRF & $8.19 E-05$ \\
\hline & Interferon signaling & $1.1 E-03$ \\
\hline & Role of RIG-like receptors in antiviral activity & $1.57 E-03$ \\
\hline & Calcium transport & $1.36 E-02$ \\
\hline \multirow[t]{5}{*}{3} & Interferon signaling & $8.29 E-15$ \\
\hline & Activation of IRF by cystosolic PRRS & $8.09 E-11$ \\
\hline & Antigen presentation pathway & $9.42 E-11$ \\
\hline & $\begin{array}{l}\text { Role of PRRs in the recognition of bacteria and } \\
\text { viruses }\end{array}$ & $8.53 E-07$ \\
\hline & $\begin{array}{l}\text { Crosstalk between dendritic and natural killer } \\
\text { cells }\end{array}$ & $1.07 E-06$ \\
\hline \multirow[t]{5}{*}{5} & Interferon signaling & $2.73 E-16$ \\
\hline & $\begin{array}{l}\text { Role of PRRs in the recognition of bacteria } \\
\text { and viruses }\end{array}$ & $1.53 E-11$ \\
\hline & Activation of IRF by cystosolic PRRs & $2.20 E-10$ \\
\hline & Dendritic cell maturation & $8.79 E-09$ \\
\hline & Antigen presentation pathway & $1.24 E-08$ \\
\hline \multirow[t]{5}{*}{7} & Interferon signaling & $7.12 E-15$ \\
\hline & $\begin{array}{l}\text { Role of PRRs in the recognition of bacteria and } \\
\text { viruses }\end{array}$ & $5.65 E-14$ \\
\hline & TREM1 signaling & $7.42 E-14$ \\
\hline & Antigen presentation pathway & $6.73 E-13$ \\
\hline & Dendritic cell maturation & $6.26 E-12$ \\
\hline \multirow[t]{5}{*}{15} & Interferon signaling & $3.31 E-13$ \\
\hline & Antigen presentation pathway & $5.67 E^{-13}$ \\
\hline & Complement system & $1.3 E-09$ \\
\hline & $\mathrm{T}$ helper cell differentiation & $7.57 E-09$ \\
\hline & Dendritic cell maturation & $9.96 E-09$ \\
\hline \multirow[t]{5}{*}{28} & Acute-phase response signaling & $7.22 E-18$ \\
\hline & LXR/RXR activation & $3.99 E-13$ \\
\hline & FXR/RXR activation & $5.56 E-13$ \\
\hline & Coagulation system & $2.97 E-10$ \\
\hline & Extrinsic prothrombin activation pathway & $1.88 E-09$ \\
\hline
\end{tabular}


interferon (IFN) signaling was a pathway that appeared at all time points, except at $28 \mathrm{dpi}$. From 3 to $15 \mathrm{dpi}$, IFN signaling was at the top ( $p$ value) of all the pathway hits, suggesting that this pathway was an important and integral part of the P. leucopus mouse brain response to POWV until very late after infection.

The IPA also enables inference of upstream regulators, i.e., molecules likely to be responsible for the observed phenotype or activation/inhibition of other molecules. This analysis suggested that TRIM24 (transcription intermediary factor $1 \alpha$ ) was inhibited at every time point from 1 to $15 \mathrm{dpi}$ (Table 4). Although TRIM24 inhibition was not in the top 5 at $7 \mathrm{dpi}$, it was in the top 10 upstream regulators with a $p$ value of $1.18 E-40$ and a $z$-score of -5.509 . This result was interesting because TRIM24 inhibits many IFN-induced genes and may also regulate the IFN response.
The other upstream regulators that were in the top $5(z-$ score and $p$ value) at each time point included IFNAR, IFN- $\alpha 2$, IFN- $\gamma$, and IRF7. IFNAR and IFN- $\gamma$ were in the top 5 at 3 to $15 \mathrm{dpi}$, whereas IFN- $\alpha 2$ ranked high at 1 to 7 dpi (Table 4).

The IPA of the data collected at 28 dpi showed that the top 5 canonical pathways at that point included acute-phase response signaling ( $p=7.218 E-18)$, activation of the liver $X$ receptor with retinoic X receptor (LXR/RXR; $p=3.99 E-13)$, and farnesoid $X$ receptor with $R X R$ (FXR/RXR; $p=5.56 E-13)$. These signaling pathways were characterized by the upregulation of genes encoding for SERPINA1 (alpha1-antitrypsin precursor); apolipoproteins A1, A2, and $\mathrm{H}$; as well as fibrinogen $\alpha, \beta$, and $\gamma$ chains. LXR/RXR and FXR/ RXR systems are involved in cholesterol homeostasis as well as counteracting inflammation. Although we did not observe

Table 4 Analysis of the top ( $p$ value) upstream regulators of the $P$. leucopus mouse brain transcriptome profiles

\begin{tabular}{|c|c|c|c|c|}
\hline Time (dpi) & Upstream regulator & Predicted activation & Activation $z$-score & $p$ value of overlap \\
\hline \multirow[t]{5}{*}{1} & TRIM24 & Inhibited & -3.0 & $5.59 E-15$ \\
\hline & IFN- $\alpha 2$ & Activated & 3.251 & $6.81 E-15$ \\
\hline & IRF7 & Activated & 3.107 & $1.03 E-14$ \\
\hline & ACKR2 & Inhibited & -2.646 & $4.10 E-14$ \\
\hline & IRF3 & Activated & 3.056 & $5.92 E-14$ \\
\hline \multirow[t]{5}{*}{3} & IFN- $\gamma$ & Activated & 7.020 & $9.28 E-47$ \\
\hline & IFN- $\alpha 2$ & Activated & 5.625 & $5.17 E-44$ \\
\hline & IRF7 & Activated & 5.348 & $1.79 E-43$ \\
\hline & TRIM24 & Inhibited & -5.042 & $2.44 E-42$ \\
\hline & IFNAR & Activated & 4.577 & $2.05 E-41$ \\
\hline \multirow[t]{5}{*}{5} & $\mathrm{IFN}-\gamma$ & Activated & 7.042 & $4.06 E-49$ \\
\hline & TRIM24 & Inhibited & -5.140 & $1.95 E-42$ \\
\hline & IRF7 & Activated & 5.348 & $4.06 E-41$ \\
\hline & IFNAR & Activated & 4.940 & $1.58 E-39$ \\
\hline & IFN- $\alpha 2$ & Activated & 5.442 & $6.85 E-38$ \\
\hline \multirow[t]{5}{*}{7} & $\mathrm{IFN}-\gamma$ & Activated & 9.425 & $1.02 E-73$ \\
\hline & IFNA2 & Activated & 6.848 & $1.41 E-57$ \\
\hline & IFNAR & Activated & 5.670 & $6.93 E-54$ \\
\hline & IFN- $\alpha$ & Activated & 6.543 & $1.13 E-50$ \\
\hline & LPS & Activated & 7.964 & $1.27 E-50$ \\
\hline \multirow[t]{5}{*}{15} & IFN- $\gamma$ & Activated & 7.045 & $8.46 E-49$ \\
\hline & IFNAR & Activated & 4.247 & $4.99 E-31$ \\
\hline & TRIM24 & Inhibited & -4.626 & $9.65 E-30$ \\
\hline & IRF7 & Activated & 4.773 & $1.74 E-27$ \\
\hline & IFN- $\alpha$ & Activated & 4.703 & $2.81 E-26$ \\
\hline \multirow[t]{5}{*}{28} & HNF1A & Activated & 2.804 & $2.94 E-13$ \\
\hline & Nitrofurantoin & Inhibited & -2.630 & $5.30 E-13$ \\
\hline & Carbon tetrachloride & - & 0.577 & $2.25 E-11$ \\
\hline & IL-6 & Activated & 2.098 & $5.57 E-11$ \\
\hline & Methapyrilene & Inhibited & -2.449 & $1.01 E-10$ \\
\hline
\end{tabular}


any obvious signs of inflammation at $28 \mathrm{dpi}$ by histopathological examination of brain sections (Mlera et al. 2017), the transcriptome profile also suggested that the acute-phase response signaling was activated (Table 3 ) and that there was activation of upstream regulators involved in inflammation, such as IL-6 (Table 4). Thus, there was a clear residual molecular footprint of inflammation in $P$. leucopus mouse brains at $28 \mathrm{dpi}$.
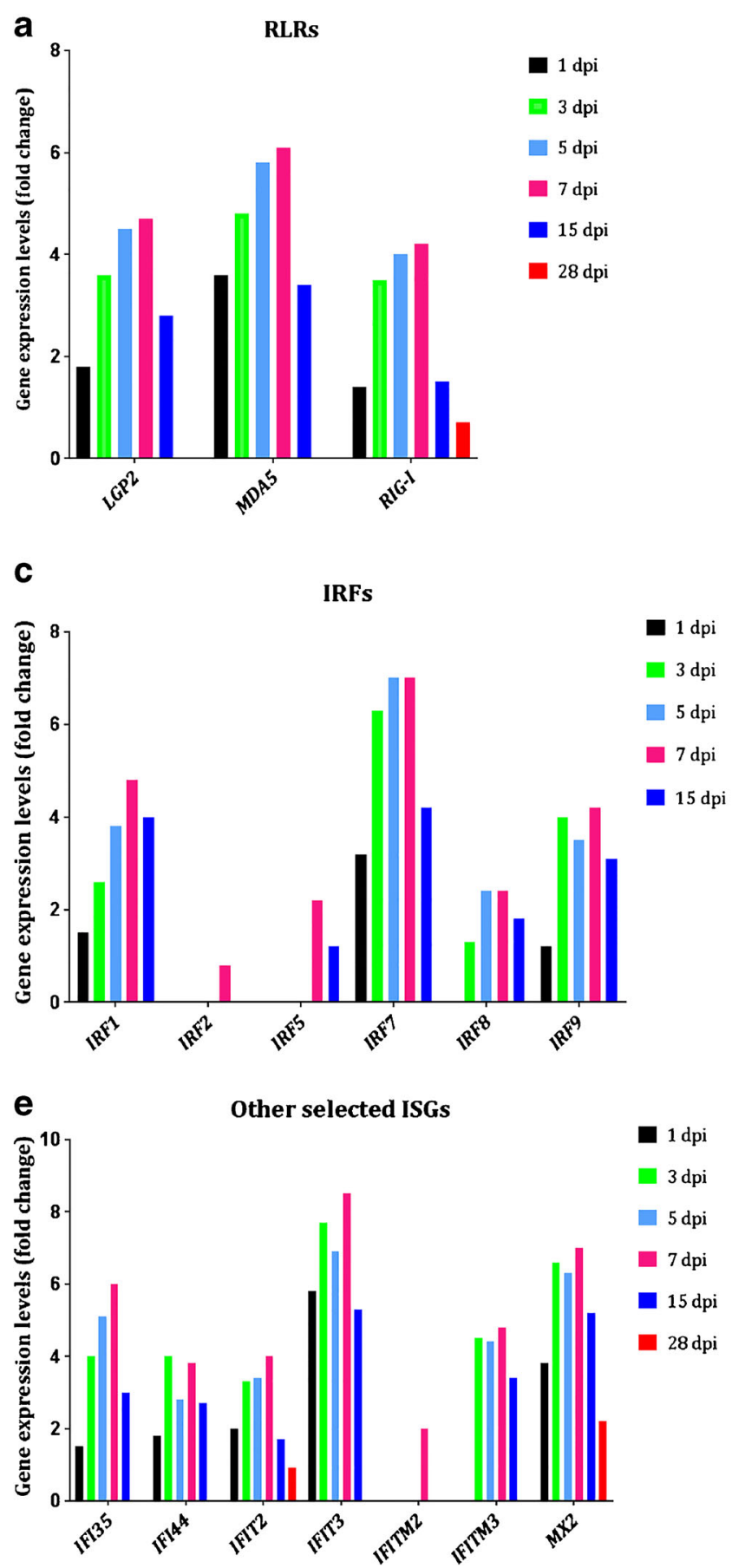

Fig. 2 Analysis of the expression level of selected genes representing RIG-like receptors (a), TLRs (b), IRFs (c), and ISGs (d, e). The expression levels are relative to the mock-infected $P$. leucopus brain samples

\section{Analysis of the expression of IFN-stimulated genes}

Initial analyses with IPA indicated that a robust IFN signaling response to POWV infection (Table 3 ). IFN signaling is activated by host cell viral RNA sensors, and our P. leucopus mouse brain transcriptome sequencing results showed the upregulation of RIG-like receptors RIG-I, MDA5, and LGP2 (Fig. 2a). In
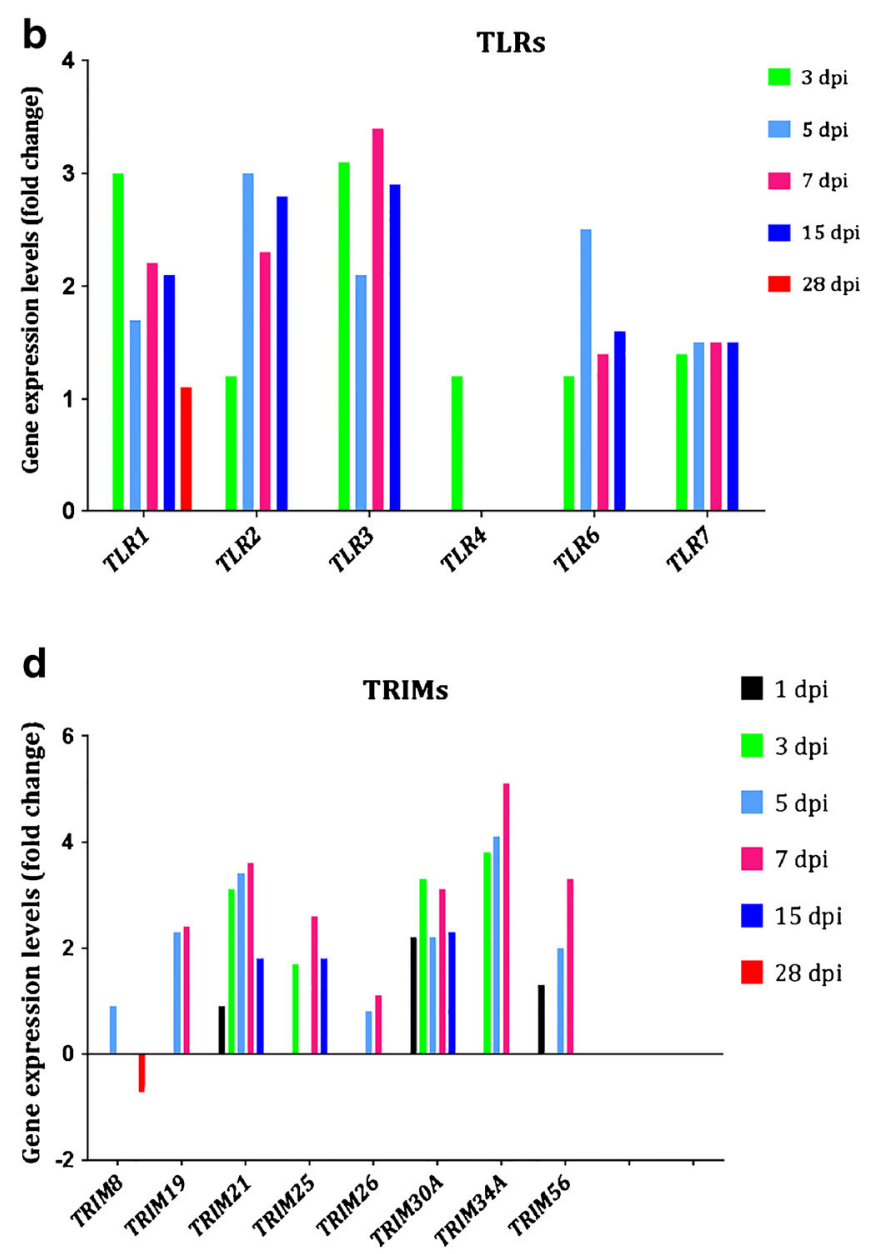
response was a prominent feature of the P. leucopus mouse brain 
addition, genes encoding Toll-like receptors TLR1-TLR4, TLR6, and TLR7 were also upregulated (Fig. 2b), suggesting that POWV-associated molecular patterns were also detected by these membrane-bound pathogen recognition receptors.

Following IFN- $\alpha$ secretion, a barrage of IFN-stimulated genes (ISGs) was expressed in an incremental fashion over time as expected (Figs. 2d, e, and 3). Some of the genes that code for the ISGs include those that code for tripartite motif (TRIM) containing proteins, and we noted that $P$. leucopus mice responded to POWV by upregulating the following array of TRIMs: TRIM8, TRIM19, TRIM21, TRIM25, TRIM26, TRIM30A (homolog of human TRIM5 $\alpha$ ), TRIM34A (TRIM6 paralog), and TRIM56. TRIM21 and TRIM30A were the only genes that were upregulated at 1 to 15 dpi (Fig. 2d), and the trend of gene expression was incremental over each of these time points, peaking at $7 \mathrm{dpi}$ and then progressively declining at 15 and 28 dpi. TRIM34A gene expression was the most upregulated at 3, 5, and $7 \mathrm{dpi}$. The upregulation of various TRIMencoding genes during POWV infection suggests that these may be playing a collective or synergistic role in virus restriction.

Other ISG-encoding genes of interest were IFIT3 and $M X 2$, which are known to have antiviral properties and were expressed to elevated levels by 7 dpi (Fig. 2e). IFIT3 was expressed to the highest level of 8.5 -fold at $7 \mathrm{dpi}$, whereas the highest expression level of $M X 2$ was 7 -fold, and it was upregulated at all time points from 1 to $28 \mathrm{dpi}$ (Fig. 2e). The upregulated expression of $M X 2$ by 28 dpi suggested that the antiviral system was still active and that MX2 might also play a crucial role in the response against POWV in P. leucopus mouse brains.

IFN secretion is controlled by IRFs, and interrogation of the RNA-Seq results showed that $I R F 1, I R F 7$, and $I R F 9$ were incrementally upregulated from $1 \mathrm{dpi}$ and the expression levels peaked at $7 \mathrm{dpi}$, before slightly declining at $15 \mathrm{dpi}$ (Fig. 2c). IRF7 gene expression was the most upregulated at each of these time points. $I R F 2$ was only significantly upregulated at $7 \mathrm{dpi}$, but the expression level was $<2$-fold. IRF5 was significantly upregulated at 7 and 15 dpi only, whereas $I R F 8$ was upregulated from 3 to $15 \mathrm{dpi}$, but at relatively lower expression levels.

\section{Validation of RNA-Seq data}

We used qRT-PCR to validate the RNA-Seq data, and for this purpose, we selected genes associated with innate immune responses, i.e., DDX58, IFIT3, STAT2, and TRIM21. Corroboration assays were performed using cDNA samples from 1-, 5-, and 15-dpi time points. The gene expression levels for DDX58, IFIT3, STAT2, and TRIM21 are shown in Fig. 4, and the Spearman correlation coefficients are listed in Table 5. The qRT-PCR data correlated well ( $p$ values in Table 5) with the RNA-Seq data; thus, we concluded that the RNA-Seq data could be used for biological inference (Table 6).

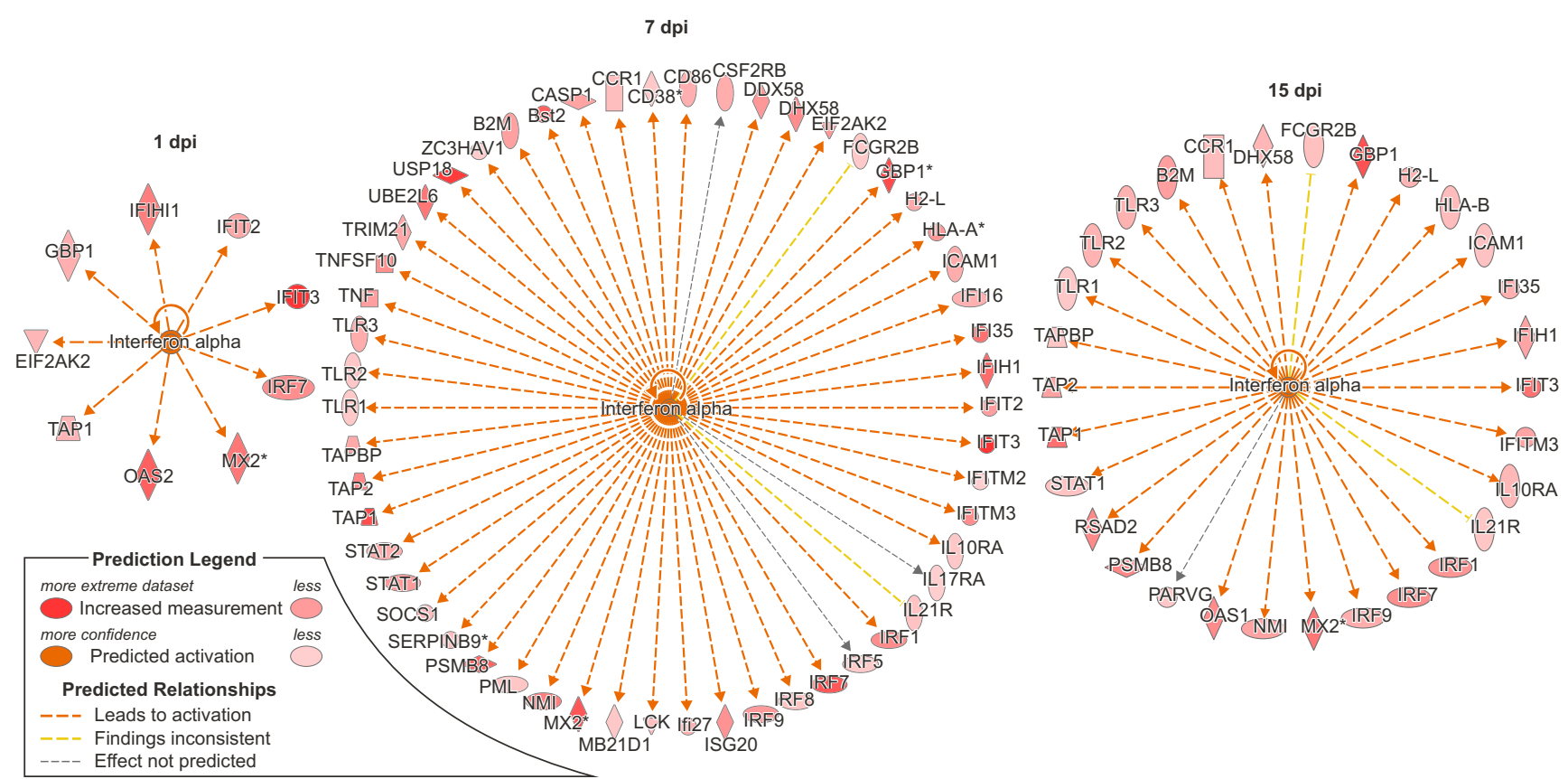

Fig. 3 IPA depicting activation of IFN- $\alpha$ and its effect on the upregulation of other genes at 1,7 , and 15 dpi. Only 9 genes were upregulated at $1 \mathrm{dpi}$, followed by a dramatic increase to 54 genes at $7 \mathrm{dpi}$, and the number declined to 30 by $15 \mathrm{dpi}$. The red color in the genes indicates upregulation, and the intensity of the color represents gene expression levels, i.e., the more intense, the more upregulated 

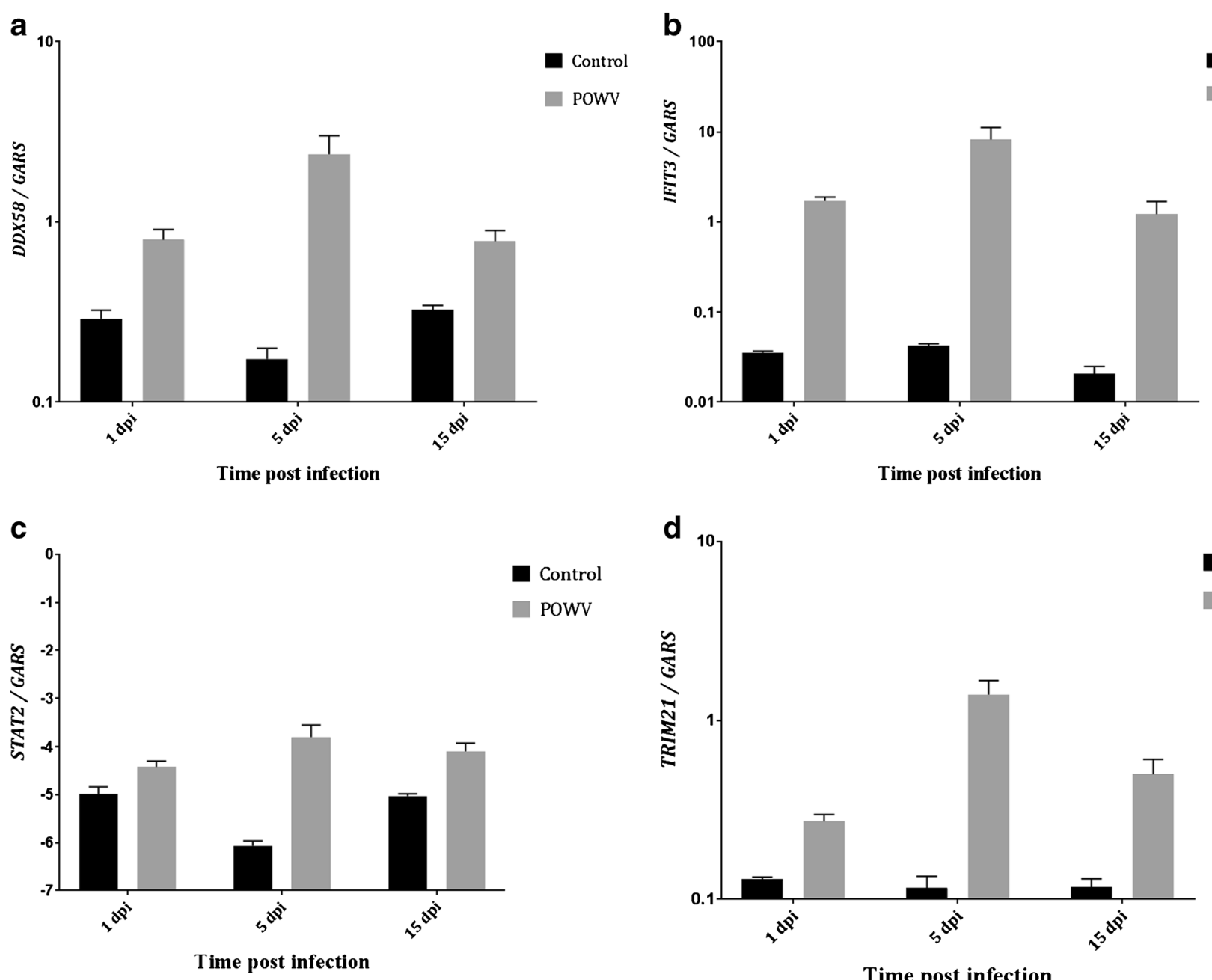

Fig. 4 Validation of next-generation sequencing (NGS) data with qRTPCR. The expression levels for each gene analyzed were relative to the expression levels of the GARS gene, and the results corroborated with the

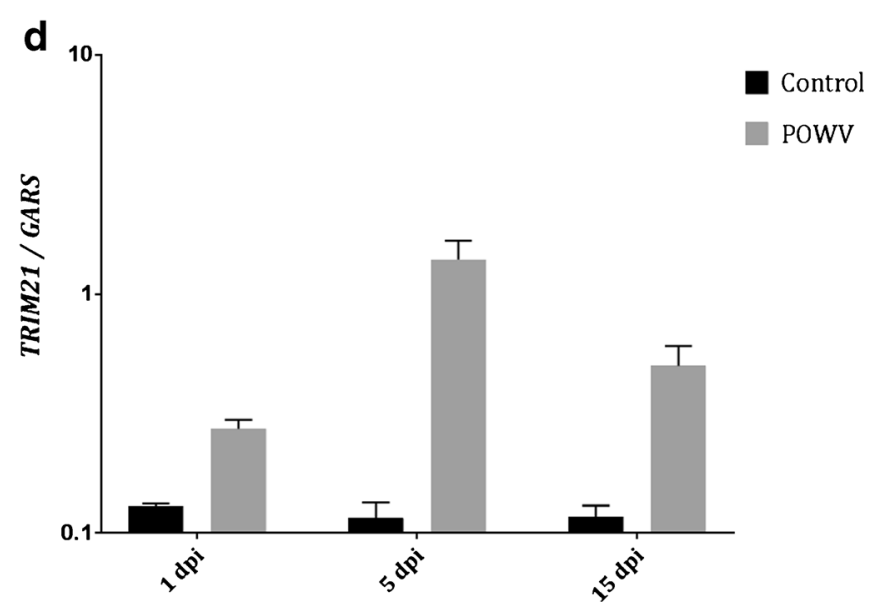

Time post infection

gene expression levels obtained by NGS (Table 5 ). The values depict the average gene expression levels for three mouse brains, and the error bars indicate the standard error of the mean (SEM)

\section{Discussion}

Powassan virus causes life-threatening encephalitis in humans. This virus is transmitted by hard-bodied Ixodes tick species, and it seems very likely that human infection with POWV is on the increase (Ebel 2010; Piantadosi et al. 2015). The Ixodes ticks obtain blood meals from small-tomedium-sized mammals, which include $P$. leucopus mice, but very little is known regarding the relationship between these animals and POWV. To improve knowledge in this subject matter, we developed a $P$. leucopus mouse model of POWV infection in which the virus does not cause obvious clinical signs of disease, but intracranial inoculation resulted in mild inflammation. Evidence of virus replication was restricted in time and space mainly to the olfactory bulb (Mlera et al. 2017). To further characterize the P. leucopus mouse brain response to POWV, we used RNA-Seq to profile the

transcriptome of intracranially inoculated $P$. leucopus mice and compared it to mock-inoculated mice.

Results of our RNA-Seq study showed that early after infection, there was a progressive increase in the number of genes that were significantly differentially expressed. The total number of significantly differentially expressed genes peaked to 232 ( \pm 2 -fold change in expression levels) at $7 \mathrm{dpi}$. By $28 \mathrm{dpi}$, the number of significantly differentially expressed genes had declined to only 28 , suggesting a wellcontrolled transcriptome response to POWV. These results were consistent with our previous observations that infectious POWV was only detectable by culture in the first 7 days of infection (Mlera et al. 2017). It is also interesting to note that intraperitoneally or intracranially inoculated 4-week-old $\mathrm{BALB} / \mathrm{c}$ mice succumb to POWV disease within the first week of infection, suggesting that there are unique factors of the $P$. leucopus mouse response that are expressed 
Table 5 qRT-PCR validation of RNA-Seq data: Spearman correlation coefficients and $p$ values

\begin{tabular}{lll}
\hline Gene & $\begin{array}{l}\text { Spearman correlation } \\
\text { coefficient }\end{array}$ & $p$ value \\
\hline STAT2 & 0.847 & $9.457 E-06$ \\
IFIT3 & 0.859 & $4.942 E-06$ \\
DDX58 & 0.875 & $2.010 E-06$ \\
TRIM21 & 0.821 & $2.980 E-05$ \\
\hline
\end{tabular}

early and critical for restricting POWV without extensive pathology in the host.

The emergent theme in the transcriptome profile was that P. leucopus mouse brains mounted a robust and wellcontrolled interferon response (Figs. 2 and 3, Tables 3 and 4) that was effective in controlling the spread of infection. This is exemplified by a change in the landscape of IFN- $\alpha$ signaling, which starts with just nine upregulated IFN-stimulated genes at $1 \mathrm{dpi}$, followed by a dramatic increase to 54 upregulated ISGs by 7 dpi (Fig. 3). Indeed, the IFN response is a wellknown potent antiviral host response system, which leads to the transcription of hundreds of virus-incapacitating ISGs (Raftery and Stevenson 2017; Wang et al. 2017). Thus, it was not surprising to see the increase in the genes affected by IFN- $\alpha$. The IFN response is also activated in the brains of Swiss Webster mice challenged with the mosquito-borne West Nile virus (WNV) or Japanese encephalitis virus, and in the brains of C57BL/6 mice challenged with WNV (Clarke et al. 2014; Kumar et al. 2016). Importantly, unlike P. leucopus mice infected with POWV, the C57BL/6 and
Swiss Webster mice develop widespread infection and neurological symptoms and succumb from disease. A recent report has shown that IFN signaling is associated with restriction of POWV replication in vitro in adult and embryonic $P$. leucopus fibroblasts, in comparison to Mus musculus fibroblast cells (Izuogu et al. 2017). In this report, the authors found that both P. leucopus and M. musculus fibroblast cells secrete IFN upon challenge with the tick-borne Langat virus and that knockdown of STAT1 or IFNAR1 increased viral replication in P. leucopus fibroblasts (Izuogu et al. 2017). Although we were not able perform direct P. leucopus and M. musculus comparisons in vivo, results from the WNV studies also suggest that the IFN response is, in and of itself, insufficient to control virus replication. This implies that there may be additional factors that restrict POWV replication and disease induction not typically associated with the control/ regulation of IFN signaling or, perhaps indeed, even novel factors completely unrelated to the classical IFN antiviral system. We are currently pursuing studies aimed at decoding the $\sim 40 \%$ RNA-Seq reads that we were unable to map to a reference genome as a way of deciphering these factors.

The specific ISGs common to early POWV replication included DDX60, GBP1, GBP4, GBP6, and $M X 2$; the products of all these genes are antiviral. DDX60 mediates its antiviral properties by binding to RIG-I to promote RIG-I-like signaling (Miyashita et al. 2011). The guanylate-binding proteins (GBPs) are IFN inducible, and GBP1 has been shown to be upregulated with an inhibitory effect during dengue virus infection (Pan et al. 2012). Our results showed that in addition to GBP1, GBP4 and GBP6 are also upregulated during POWV infection. Similar results have been reported for WNV infection in Swiss Webster mice (Clarke et al. 2014).

Table 6 Primers used for q-RT-PCR validation of RNA-Seq data

\begin{tabular}{|c|c|c|c|}
\hline Gene & Accession & Oligo type & $5^{\prime}-3^{\prime}$ sequence \\
\hline \multirow[t]{3}{*}{ STAT2 } & \multirow[t]{3}{*}{ NM_019963 } & Forward & CCGAAGTCCCAAATTAAGCC \\
\hline & & Reverse & AGCGAATCACTCAAAGCAGA \\
\hline & & 5' 6-FAM/ZEN/3IABkFQ 3' & CCGGAAGCCTGGTAAGTCTGAATTCC \\
\hline \multirow[t]{3}{*}{ IFIT3 } & \multirow[t]{3}{*}{ NM_010501 } & Forward & CTTCAGCTGTGGAAGGATCG \\
\hline & & Reverse & CACACCCAGCTTTTCCCA \\
\hline & & 5' 6-FAM/ZEN/3IABkFQ 3' & CACCATCATGAGTGAGGTCAACCGG \\
\hline \multirow[t]{3}{*}{$D D X 58$} & \multirow[t]{3}{*}{ NM_172689 } & Forward & CCTTGTTGTTCTTCTCAGCCT \\
\hline & & Reverse & CCACCTACATCCTCAGCTACA \\
\hline & & 5' 6-FAM/ZEN/3IABkFQ 3' & TGTACTGCACCTCCTCATCCTCGA \\
\hline \multirow[t]{3}{*}{ TRIM21 } & \multirow[t]{3}{*}{ NM_009277 } & Forward & CTTTGATCCTTCTCCAGCCT \\
\hline & & Reverse & CACGATGCAAAGAACAGACTG \\
\hline & & 5' 6-FAM/ZEN/3IABkFQ 3' & ATTCACGCAGAGTTCGCACTTCAGA \\
\hline \multirow[t]{3}{*}{ GARS } & \multirow[t]{3}{*}{ NM_180678 } & Forward & GTCAGCACATCCAACAATCTC \\
\hline & & Reverse & CTCCTGATAAACTCCGCTTCC \\
\hline & & 5' HEX/ZEN/3IABkFQ 3' & CCGAGTCCAAAACGTCCTATGGCT \\
\hline
\end{tabular}


The use of IPA enables us to observe that TRIM24 was inhibited over the entire course of POWV infection. This was an interesting finding because TRIM24 is proposed to be a negative regulator of IFN signal transducers and activators through retinoic acid receptor alpha (RARA). In TRIM24 knockout cells, many ISGs, genes such as IFIT2, IFIT3, and IFIH1, were found to be TRIM24-dependent (Tisserand et al. 2011). POWV does not replicate to high titers in P. leucopus mouse brains, and the suppression of TRIM24 suggests that this molecule may be a crucial factor in controlling the IFN response and, subsequently, POWV replication. Thus, further experiments to explore the role of TRIM24 in POWV replication or host response are warranted.

In contrast to TRIM24, genes that code for several other TRIMs were upregulated in expression and these included TRIM19, TRIM21, TRIM25, TRIM30A, and TRIM34A (Fig. 2d). There is a cornucopia of TRIMs, and they have varied functions, including cell proliferation, differentiation, as well as antiviral activity (Nisole et al. 2005; Rajsbaum et al. 2008). TRIM79 $\alpha$ is rodent-specific and was shown to inhibit the tick-borne Langat virus by targeting the RNA-dependent RNA polymerase (NS5) for lysosomal degradation (Taylor et al. 2011). The precise role of the TRIMs we identified is unclear, and it will be interesting to delineate the specific role played by each one of the TRIMs identified in our study with POWV. In vitro modeling with $P$. leucopus cells may prove a more tractable system for elucidating these complicated networks, and we are currently undertaking this work.

The 28-dpi differential gene expression profile was different from the rest of the time points we analyzed. This was not unexpected, considering that the times were far apart and that the persistent POWV RNA was no longer associated with any infectious POWV (Mlera et al. 2017). However, it was interesting that we did not observe any signs of inflammation at 28 dpi by histology (Mlera et al. 2017), but the IPA suggested that some elements of the acute-phase response signaling remained active, indicative of inflammation. In addition, the IPA of the 28-dpi gene set indicated the activation of the LXR/ RXR and FXR/RXR systems (Table 3). LXR is a heterodimeric transcription factor involved in cholesterol metabolism, and it also has anti-inflammatory activity (Tall and YvanCharvet 2015). LXR has been reported to have antiviral activity for several viruses. For example, stimulation of the LXR with LXR agonists resulted in potent inhibition of HIV replication in a humanized mouse model (Ramezani et al. 2015). Nakajima et al. showed that neoechinulin B inhibits LXR and subsequently inhibits HCV replication because it reduced double-membrane vesicles in which HCV replication occurs (Bocchetta et al. 2014; Nakajima et al. 2016; Zeng et al. 2012). Langat virus and the mosquito-borne Zika virus also cause an expansion of membrane-bound vesicles in the endoplasmic reticulum (Offerdahl et al. 2012, 2017), suggesting that blocking LXR could inhibit POWV replication, a hypothesis that needs further study. In contrast, the LXR/RXR genes seem to have a pro-viral effect in the case of Coxsackie virus B3 (CVB3), and it does not reduce cardiac inflammation in vivo, predisposing mice to mortality upon infection (Papageorgiou et al. 2015). At present, we are uncertain of the role of $\mathrm{LXR} / \mathrm{RXR}$ and FXR/RXR activation during POWV infection and this merits further study.

In summary, we determined the brain transcriptome profile of $P$. leucopus mice following intracranial inoculation with POWV and compared the results to those of mockinoculated animals. There was an increase in the number of genes that were significantly differentially expressed from 1 to $7 \mathrm{dpi}$, followed by a decline at 15 and $28 \mathrm{dpi}$. The IPA of the genes at 1 to $15 \mathrm{dpi}$ indicates that $P$. leucopus mice infected with POWV mount a robust IFN response, which is characterized by the upregulation of many antiviral genes. Some of the induced genes include $G B P 1, G B P 4, G B P 6$, several TRIMs, and $M X 2$. As mentioned earlier, further studies and development of in vitro systems will prove valuable to delineate restriction factors of POWV, and these results will be useful for studies aimed at the development of POWV antiviral therapies.

Acknowledgements We thank Dr. Craig Martens, Dan Sturdevant, and the staff in the Rocky Mountain Veterinary Branch for their technical assistance. We also appreciate the members of the Biology of VectorBorne Viruses Section and the Laboratory of Virology for their useful discussions. In addition, we are grateful to Mr. Ryan Kissinger for assistance with graphic art.

Funding information This study was supported by the Division of Intramural Research of the National Institute of Allergy and Infectious Disease, National Institutes of Health.

Compliance with ethical standards All mouse work was ethically done in animal biosafety level 3 (BSL3) facilities according to approved animal study protocols (Mlera et al. 2017).

Conflict of interest The authors declare that they have no conflict of interest.

Open Access This article is distributed under the terms of the Creative Commons Attribution 4.0 International License (http:// creativecommons.org/licenses/by/4.0/), which permits unrestricted use, distribution, and reproduction in any medium, provided you give appropriate credit to the original author(s) and the source, provide a link to the Creative Commons license, and indicate if changes were made.

\section{References}

Bedford NL, Hoekstra HE (2015) Peromyscus mice as a model for studying natural variation. eLife 4:e06813

Bocchetta S, Maillard P, Yamamoto M, Gondeau C, Douam F, Lebreton S, Lagaye S, Pol S, Helle F, Plengpanich W, Guérin M, Bourgine M, Michel ML, Lavillette D, Roingeard P, le Goff W, Budkowska A 
(2014) Up-regulation of the ATP-binding cassette transporter A1 inhibits hepatitis C virus infection. PLoS One 9:e92140

Clarke P, Leser JS, Bowen RA, Tyler KL (2014) Virus-induced transcriptional changes in the brain include the differential expression of genes associated with interferon, apoptosis, interleukin 17 receptor $\mathrm{A}$, and glutamate signaling as well as flavivirus-specific upregulation of tRNA synthetases. MBio 5:00902-00914

Deardorff ER, Nofchissey RA, Cook JA, Hope AG, Tsvetkova A, Talbot SL, Ebel GD (2013) Powassan virus in mammals, Alaska and New Mexico, U.S.A., and Russia, 2004-2007. Emerg Infect Dis 19:20122016

Dobler G (2010) Zoonotic tick-borne flaviviruses. Vet Microbiol 140: 221-228

Dupuis IIA, Peters R, Prusinski M, Falco R, Ostfeld R, Kramer L (2013) Isolation of deer tick virus (Powassan virus, lineage II) from Ixodes scapularis and detection of antibody in vertebrate hosts sampled in the Hudson Valley, New York State. Parasit Vectors 6:185

Ebel GD (2010) Update on Powassan virus: emergence of a North American tick-borne flavivirus. Annu Rev Entomol 55:95-110

Frey S, Essbauer S, Zöller G, Klempa B, Weidmann M, Dobler G, Pfeffer M (2013) Complete genome sequence of tick-borne encephalitis virus strain A104 isolated from a yellow-necked mouse (Apodemus flavicollis) in Austria. Genome Announcements 1: e00564-e00513

Gholam BI, Puksa S, Provias JP (1999) Powassan encephalitis: a case report with neuropathology and literature review. CMAJ: Can Med Ass J 161:1419-1422

Heinz FX, Kunz C (2004) Tick-borne encephalitis and the impact of vaccination. Arch Virol Suppl:201-205

Heinz FX, Stiasny K, Holzmann H, Grgic-Vitek M, Kriz B, Essl A, Kundi M (2013) Vaccination and tick-borne encephalitis, Central Europe. Emerg Infect Dis 19:69-76

Hermance ME, Thangamani S (2015) Tick saliva enhances Powassan virus transmission to the host influencing its dissemination and the course of disease. J Virol 89:7852-7860

Hermance ME, Thangamani S (2017) Powassan virus: an emerging arbovirus of public health concern in North America. Vector-Borne Zoonotic Dis 17:453-462

Hinten SR, Beckett GA, Gensheimer KF, Pritchard E, Courtney TM, Sears SD, Woytowicz JM, Preston DG, Smith RP, Jr., Rand PW, Lacombe EH, Holman MS, Lubelczyk CB, Kelso PT, Beelen AP, Stobierski MG, Sotir MJ, Wong S, Ebel G, Kosoy O, Piesman J, Campbell GL, Marfin AA (2008). Increased recognition of Powassan encephalitis in the United States, 1999-2005. Vector Borne Zoonotic Dis 8: 733-740

Izuogu AO, McNally KL, Harris SE, Youseff BH, Presloid JB, Burlak C, Munshi-South J, Best SM, Taylor RT (2017) Interferon signaling in Peromyscus leucopus confers a potent and specific restriction to vector-borne flaviviruses. PLoS One 12:e0179781

Kentaro Y, Yamazaki S, Mottate K, Nagata N, Seto T, Sanada T, Sakai M, Kariwa H, Takashima I (2013) Genetic and biological characterization of tick-borne encephalitis virus isolated from wild rodents in southern Hokkaido, Japan in 2008. Vector Borne Zoonotic Dis 13: 406-414

Kim D, Pertea G, Trapnell C, Pimentel H, Kelley R, Salzberg S (2013) TopHat2: accurate alignment of transcriptomes in the presence of insertions, deletions and gene fusions. Genome Biol 14:R36

Kim S-Y, Yun S-M, Han MG, Lee IY, Lee NY, Jeong YE, Lee BC, Ju YR (2008) Isolation of tick-borne encephalitis viruses from wild rodents, South Korea. Vector-Borne Zoonotic Dis 8:7-14

Kumar M, Belcaid M, Nerurkar VR (2016) Identification of host genes leading to West Nile virus encephalitis in mice brain using RNA-seq analysis. Scientific Rep 6:26350

Labuda M, Jones LD, Williams T, Danielova V, Nuttall PA (1993a) Efficient transmission of tick-borne encephalitis virus between cofeeding ticks. J Med Entomol 30:295-299
Labuda M, Nuttall PA, Kozuch O, Eleckova E, Williams T, Zuffova E, Sabo A (1993b) Non-viraemic transmission of tick-borne encephalitis virus: a mechanism for arbovirus survival in nature. Experientia 49:802-805

Labuda M, Kozuch O, Zuffova E, Eleckova E, Hails RS, Nuttall PA (1997) Tick-borne encephalitis virus transmission between ticks cofeeding on specific immune natural rodent hosts. Virology 235: $138-143$

Leonova G, Kondratov I, Ternovoi V, Romanova E, Protopopova E, Chausov E, Pavlenko E, Ryabchikova E, Belikov S, Loktev V (2009) Characterization of Powassan viruses from Far Eastern Russia. Arch Virol 154:811-820

Lindsey NP, Lehman JA, Staples JE, Fischer M (2015) West Nile virus and other nationally notifiable arboviral diseases - United States, 2014. MMWR Morb Mortal Wkly Rep 64:929-934

Main AJ, Carey AB, Downs WG (1979) Powassan virus in Ixodes cookei and mustelidae in New England. J Wildl Dis 15:585-591

McLean DM, Donohue WL (1959) Powassan virus: isolation of virus from a fatal case of encephalitis. Can Med Assoc J 80:708-711

Miyashita M, Oshiumi H, Matsumoto M, Seya T (2011) DDX60, a $\mathrm{DEXD} / \mathrm{H}$ box helicase, is a novel antiviral factor promoting RIGI-like receptor-mediated signaling. Mol Cell Biol 31:3802-3819

Mlera L, Meade-White K, Saturday G, Scott D, Bloom ME (2017) Modeling Powassan virus infection in Peromyscus leucopus, a natural host. PLoS Neg Trop Dis 11:e0005346

Mlera L, Melik W, Bloom ME (2014) The role of viral persistence in flavivirus biology. Pathog Dis 71:137-163

Nakajima S, Watashi K, Ohashi H, Kamisuki S, Izaguirre-Carbonell J, Kwon AT-J, Suzuki H, Kataoka M, Tsukuda S, Okada M, Moi ML, Takeuchi T, Arita M, Suzuki R, Aizaki H, Kato T, Suzuki T, Hasegawa H, Takasaki T, Sugawara F, Wakita T (2016) Fungusderived neoechinulin $\mathrm{B}$ as a novel antagonist of liver $\mathrm{X}$ receptor, identified by chemical genetics using a hepatitis $\mathrm{C}$ virus cell culture system. J Virol 90:9058-9074

Nisole S, Stoye JP, Saib A (2005) TRIM family proteins: retroviral restriction and antiviral defence. Nat Rev Micro 3:799-808

Offerdahl DK, Dorward DW, Hansen BT, Bloom ME (2012) A threedimensional comparison of tick-borne flavivirus infection in mammalian and tick cell lines. PLoS One 7:e47912

Offerdahl DK, Dorward DW, Hansen BT, Bloom ME (2017) Cytoarchitecture of Zika virus infection in human neuroblastoma and Aedes albopictus cell lines. Virology 501:54-62

Pan W, Zuo X, Feng T, Shi X, Dai J (2012) Guanylate-binding protein 1 participates in cellular antiviral response to dengue virus. Virology $\mathrm{J}$ 9:292

Papageorgiou A-P, Heggermont W, Rienks M, Carai P, Langouche L, Verhesen W, De Boer RA, Heymans S (2015). Liver X receptor activation enhances CVB3 viral replication during myocarditis by stimulating lipogenesis. Cardiovasc Res 107: 78-88

Pastula DM, Smith DE, Beckham JD, Tyler KL (2016) Four emerging arboviral diseases in North America: Jamestown Canyon, Powassan, chikungunya, and Zika virus diseases. J NeuroVirol 22: 257-260

Pedersen K, Wang E, Weaver SC, Wolf PC, Randall AR, Van Why KR, Travassos Da Rosa APA, Gidlewski T (2017). Serologic evidence of various arboviruses detected in white-tailed deer (Odocoileus virginianus) in the United States. Am J Trop Med and Hyg 97: 319-323

Perkins SE, Cattadori IM, Tagliapietra V, Rizzoli AP, Hudson PJ (2003) Empirical evidence for key hosts in persistence of a tick-borne disease. Int J Parasitol 33:909-917

Piantadosi A, Rubin DB, McQuillen DP, Hsu L, Lederer PA, Ashbaugh CD, Duffalo C, Duncan R, Thon J, Bhattacharyya S, Basgoz N, Feske SK, Lyons JL (2015) Emerging cases of Powassan virus encephalitis in New England: clinical presentation, imaging, and review of the literature. Clin Infect Dis 62:707-713 
Raftery N, Stevenson NJ (2017) Advances in anti-viral immune defence: revealing the importance of the IFN JAK/STAT pathway. Cell Mol Life Sci: $1-11$

Rajsbaum R, Stoye JP, O'Garra A (2008) Type I interferon-dependent and -independent expression of tripartite motif proteins in immune cells. Eur J Immunol 38:619-630

Ramezani A, Dubrovsky L, Pushkarsky T, Sviridov D, Karandish S, Raj DS, Fitzgerald ML, Bukrinsky M (2015) Stimulation of liver X receptor has potent anti-HIV effects in a humanized mouse model of HIV infection. J Pharmacol Exp Ther 354:376-383

Santos R, Hermance M, Gelman B, Thangamani S (2016) Spinal cord ventral horns and lymphoid organ involvement in Powassan virus infection in a mouse model. Viruses 8:220

Simon S, Alysse GW, Susan W, Karen K, Laura DK, Robin F, James Kirkland R, Simon T (2013) Powassan meningoencephalitis, New York, New York, USA. Emerg Infect Dis 19:1504

Takeda T, Ito T, Osada M, Takahashi K, Takashima I (1999) Isolation of tick-borne encephalitis virus from wild rodents and a seroepizootiologic survey in Hokkaido, Japan. Am J Trop Med Hyg 60:287-291

Tall AR, Yvan-Charvet L (2015) Cholesterol, inflammation and innate immunity. Nat Rev Immunol 15:104-116

Taylor RT, Lubick KJ, Robertson SJ, Broughton JP, Bloom ME, Bresnahan WA, Best SM (2011) TRIM79alpha, an interferon- stimulated gene product, restricts tick-borne encephalitis virus replication by degrading the viral RNA polymerase. Cell Host Microbe 10:185-196

Tisserand J, Khetchoumian K, Thibault C, Dembélé D, Chambon P, Losson R (2011) Tripartite motif 24 (Trim $24 /$ Tif1 $\alpha$ ) tumor suppressor protein is a novel negative regulator of interferon (IFN)/signal transducers and activators of transcription (STAT) signaling pathway acting through retinoic acid receptor $\alpha(\operatorname{RAR} \alpha)$ inhibition. J Biol Chem 286:33369-33379

Tonteri E, Jaaskelainen AE, Tikkakoski T, Voutilainen L, Niemimaa J, Henttonen H, Vaheri A, Vapalahti O (2011) Tick-borne encephalitis virus in wild rodents in winter, Finland, 2008-2009. Emerg Infect Dis 17:72-75

Trapnell C, Hendrickson DG, Sauvageau M, Goff L, Rinn JL, Pachter L (2013) Differential analysis of gene regulation at transcript resolution with RNA-seq. Nat Biotech 31:46-53

Wang W, Xu L, Su J, Peppelenbosch MP, Pan Q (2017) Transcriptional regulation of antiviral interferon-stimulated genes. Trends Microbiol 25:573-584

Zeng J, Wu Y, Liao Q, Li L, Chen X, Chen X (2012) Liver X receptors agonists impede hepatitis $\mathrm{C}$ virus infection in an idol-dependent manner. Antivir Res 95:245-256 